whole hog' and provide automatic stabilization of the tube in accordance with his (2) on page 359 . This in fact was done in both the Argus and Predictor radars.

My only serious criticism of Captain Stewart's proposals is his suggested inclusion of a relative bearing scale. Our view has been that, so long as the radar provides means for accurately reading off true bearings, and means for placing a marker on a desired compass bearing upon which it will then remain constant regardless of yawing or alteration in course, there is no necessity in merchant ships for any means on the radar for reading off relative bearings. Elimination of the relative bearing scale makes for greater clarity, and makes impossible the blunder of reading one scale in mistake for the other.

Information coming back to us from sea, where Argus stabilized screen radar has been in use for 7 years, strongly suggests that there is no real need for a relative bearing scale in addition to a true bearing scale. Similarly in regard to the self-plotting radar Predictor, this has now been used in earnest and critically examined by about a score of sea-going officers and specialists. Although there have been plenty of suggestions for improvements in the arrangement of controls, most of which have been adopted, not a single officer has lamented the absence in any form of a relative bearing scale. The picture itself, when operated ship'shead-up, provides relative bearing indications rather than precise readings, and these in respect of relative bearings are all that are needed.

\title{
Sailing Vessels and the Collision Regulations
}

\section{Michael Richey}

IT is to be hoped that before the Collision Regulations are revised in any sense that affects the rights and obligations of sailing vessels, people with practical experience of navigation under sail will be consulted. It looks as though their advice will be needed.

One increasingly hears, for example, that under modern conditions steam should no longer be required to give way to sail. 'It seems quite unreasonable now'-Captain Dickson, for instance, expresses it in the last number of the Journal $(\mathbf{2 2}, 448)$-'to expect in most cases that sailing vessels should be required to stand on for power-driven vessels'. But the reason a power-driven vessel is required to give way to sail is not some kind of old world courtesy, but that if there is no wind, the sailing vessel is immobilized: it cannot give way.

Again in the current number (p. 89) Captain Thompson in the course of his excellent cockshy at a revised set of Collision Regulations would omit, in his Rule 4, any distinction between the rights of sailing vessels running free and close-hauled. But anyone who has made up to windward in a sailing vessel knows how much more ground stands to be lost by an alteration of course by a vessel close-hauled than one running free.

These are only two examples of how things can be seen too exclusively from a steamship point of view. But the overriding need at the moment is for a thorough 
examination of the problem of injecting sailing vessels into a predominantly power-driven traffic system. If Rules 17 and 20 now appear inadequate it is because the situation has changed so radically since they were drawn up. Sailing vessels now are very much smaller, very much slower and very much more numerous. This introduces new problems. It is idle to expect, for example, that they will keep clear of shipping lanes, for it will be held that the high seas belong to everybody; and not very helpful to suggest that they must take the consequences if they enter them. What is needed is that the present situation, which is likely to get worse rather than better, is taken fully into account when the revision of the Collision Regulations and the introduction of traffic separation schemes are contemplated. It will help if those who engage in this seemingly nefarious pastime are at some stage brought into the picture.

\section{Captain Dickson comments:}

The point I wished to make was that it is unreasonable in any circumstances to have rules which require one vessel to stand on for another. My basic concern is that in all circumstances, except where one of the ships is an overtaking vessel, wherever collision risk exists both ships should be required to manceuvre to avoid collision, that these instructions should apply in clear weather or in low visibility and should not distinguish various classes of ships, sailing vessels included. Quite obviously there will be cases when ships will not, for a whole number of reasons, be able to comply with this requirement, and in those circumstances they will have to be relieved of the onus to mancuvre. I would include sailing vessels in this category, the classic example being a sailing vessel becalmed which obviously cannot manœuvre. 